MATEC Web of Conferences 22,05009 (2015)

DOI: $10.1051 /$ matecconf/ 20152205009

(C) Owned by the authors, published by EDP Sciences, 2015

\title{
A Study on the Fluid Mechanics Performance of Aquatics Equipment
}

\author{
Jian Jiao \\ Basic Teaching Center, Ocean University of China, Qingdao, Shandong, China \\ Shugang Zhang \\ College of Information Science and Engineering, Ocean University of China, Qingdao, Shandong, China
}

\begin{abstract}
As a new kind of sport, aquatics have been accepted by general sports enthusiasts. Sports, such as rowing, canoeing, fin swimming, windsurfing, sailing and water polo, have become events of the Olympic Games. Competitions among countries are quite fierce.

Based on the theoretical foundation of fluid mechanics performance, this paper carries out an analysis on mechanical characteristics of aquatic sports. First, basic features of windsurfing are studied in this paper. Performance of windsurfing changes with its parameters, requiring a lot for windsurfers. It can be known from variance analysis that the best performance of NP plate and a relatively small resistance should be the direction of sailboard design. Meanwhile, by building up a mathematical model with fuzzy comprehensive evaluation and correlation analysis, it can be also found that the fluid resistance characteristic is a key factor that influences the performance of windsurfers. Besides, this paper also takes into account external factors, including the influences of regional difference on aquatic events. Different regions with various geographical conditions have different influences on aquatic events.
\end{abstract}

Keywords: aquatics; fluid mechanics; resistance characteristic; regional difference

\section{INTRODUCTION}

With the continuous development of the science and technology globalization in the $21^{\text {st }}$ century, traditional ideas in China are constantly refreshed by new ideas. The nature of science is added not only in education but also in relevant aquatics. Studies on the application of fluid mechanics in aquatics carried out by scholars in China are presented as follows. Corresponding viewpoints and conclusions are drawn based on the study on literatures of scholars.

In his paper Research Progress of the Fluid Mechanics of Aquatic Equipment in China, Yong $\mathrm{Ma}$ carries out a specific research on the fluid mechanics of aquatics in China based on the principle of authentic academy and representative data, and provides technical references for the development of aquatics in China. This paper indicates that studies on aquatics in China are earlier than those in other countries. Aquatic events in our country now include windsurfing, canoeing, skateboarding, rowing, and so on. Although preferable performances are obtained in aquatic events internationally, skills remain to be further improved. Studies on fluid mechanics make aquatics in China more scientific and lay a solid foundation for better performance.

In the paper Application Status of Fluid Mechanics in Aquatics in China, Weitao Zheng analyzes aquatic events in China and points out the necessity of the application of fluid mechanics in aquatics. The most important factor influencing the performance of aquatic events is resistance, which can be reduced as much as possible through studies on fluid mechanics. For example, improvements can be made in terms of the design of the skateboard and clothing of athletes so that the principle of minimum resistance can be satisfied. Thus, aquatic events in China can be more scientific with better performance

Dongyan Zhang has made researches on aquatic Olympic events for a long time and gained sufficient experience in this field. Several aquatic events in the Olympic Games and relevant performances of China are analyzed in the paper Development Characteristics of Aquatic Olympic Events in China and the Analysis on Training and Management Factors. It is concluded that performances of aquatic events in our country are quite general. Main reasons include training mode of athletes, selection of equipment, design of clothing, instructions of coaches, and so on. Fluid mechanics is rarely applied in aquatics. Solutions are proposed in line with related problems.

By using research achievements of multiple scholars for reference and conducting a quantitative and analytical comparison with mathematical methods, this paper specifically analyzes the application condition of fluid mechanics in aquatics in China based on the theoretical foundation of fluid mechanics performance. It also analyzes mechanical properties of aquatics from the angle of windsurfing, indicates key factors, proposes relevant suggestions for related problems, and provides a direction for the development of aquatics in China. 


\section{MATEC Web of Conferences}

\section{ESTABLISHMENT OF MODELS}

Aquatic events mainly include water bicycle, diving, canoeing, windsurfing, water polo, etc. Aquatics have been developing extremely fast in recent years, bringing a great impact on the Olympic Games and the Asian Games. It is also quite important to carry out studies on fluid mechanics performance of aquatic equipment like accessories of single/double rowing and single/double canoeing.

\subsection{Research basis}

Fluid mechanics is a discipline that studies relevant laws and motion states of moving fluids and gases The development and design of high-performance sports equipment can be provided with a basis by applying fluid mechanics to the study on aquatics equipment and by simulating relevant fluid properties of aquatics equipment with theoretical knowledge of aerodynamics and fluid mechanics as well as computer software like CFD and CFX.

Studies on fluid mechanics are mainly carried out from three aspects, namely theory, experiment and numerical simulation. The three aspects complement each other and none can be dispensed with. The working process is presented below:

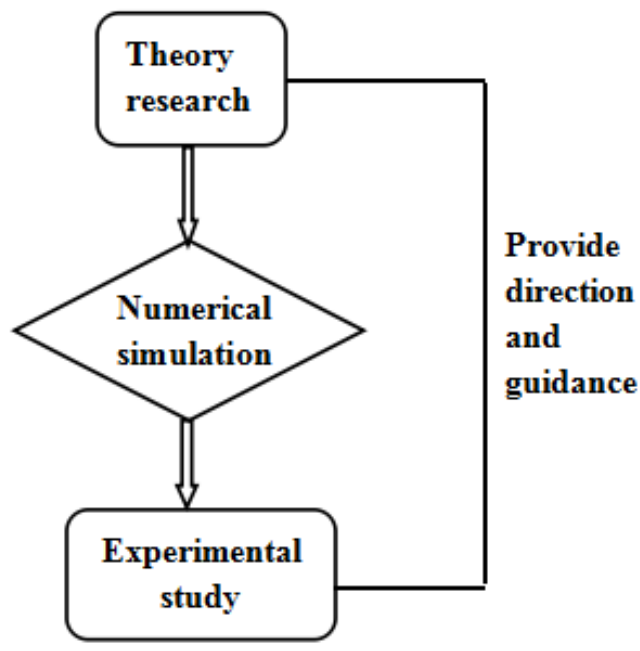

Figure 1. The main research method of fluid mechanics

According to physical characteristics of athletes, the multi-disciplinary design optimization $(M D O)$ combines physiology, biology kinematics, sports medicine and other disciplines together and couples the theoretical knowledge of each discipline so as to achieve the goal of performance research of aquatic sports equipment. The main feature is that comprehensive physical qualities of athletes are taken into account with the combination of multiple disciplines.

Numerical simulation is a computer technology widely used in the fluid mechanics research. Comprehensive analyses can be carried out on mechanical properties of aquatics equipment with the finite element method, the finite difference method, the discretization method, and so on. FLUENT is a widely used method, which presents fluid properties of aquatics equipment in the flow field, the temperature field and the velocity field with cloud charts.

\subsection{Windsurfing}

\subsubsection{A brief introduction of windsurfing}

Windsurfing originated from Hawaii in the 1980s, where large sea waves provide windsurfing with more favorable wind and wave conditions. Shapes and materials of sailboard have evolved constantly since then. Many scientists have conducted specific analyses on dynamics and fluid mechanics in order to make sailboards more adaptable to the effect of wind

\subsubsection{Sailboard design and the study on its dynamics properties based on the variance analysis}

(1) Parametric statistics of sailboard design

The decisive factor of windsurfing is the design of the sailboard. However, our country has been short of resources due to the further exploitation of resources since 1980s. This also stimulates scientists in our country to carry out further studies on the new wind energy. The research on the fluid mechanics of windsurfing starts to develop subsequently and stimulates aquatic sports to some extent.

In this paper, the author takes Windsurfer plate, Mistral plate, circular plate and NP plate as examples to study the different fluid resistance characteristics of different plates with various parameters. The speed of a windsurfing athlete represents the resistance. The faster the speed is, the smaller the resistance will be. Statistical data are as follows:

Table1. Parameters of different sailboards

\begin{tabular}{|c|c|c|c|c|}
\hline Types & $\begin{array}{l}\text { Windsurfer } \\
\text { plate }\end{array}$ & $\begin{array}{l}\text { Mistral } \\
\text { plate }\end{array}$ & $\begin{array}{l}\text { Circular } \\
\text { plate }\end{array}$ & $\begin{array}{l}\mathrm{NP} \\
\text { plate }\end{array}$ \\
\hline Area $\left(\mathrm{m}^{2}\right)$ & 6.25 & 6.33 & 6.45 & 6.13 \\
\hline Boom (m) & 4.3 & 4.4 & 4.6 & 4.1 \\
\hline $\begin{array}{l}\text { Maximum } \\
\text { camber }(\mathrm{m})\end{array}$ & 2.18 & 2.20 & 2.30 & 2.05 \\
\hline Length (m) & 3.5 & 3.9 & 3.0 & 2.6 \\
\hline Heel(degree) & 10 & 10 & 25 & 3 \\
\hline
\end{tabular}

(2) Establishment of the variance analysis model

Variance analysis aims at considering the influence of factors on indexes. Experimental results of the research object are indexes. Control variables and conditions are factors. Two-factor analysis of variance should be considered when there are two factors influencing the research object.

The mathematic model: suppose $A$ has $\mathrm{r}$ levels, $A_{1}, A_{2}, \cdots, A_{r}$, and $B$ has s levels, $B_{1}, B_{2}, \cdots, B_{s}$. The totality of $X_{i j}$ obeys the normal distribution $N\left(\mu_{i,}, \delta^{2}\right), i=1,{ }^{i j} \cdot r, j=1, \cdots, s$ in the level combination $\left(A_{i}, B_{j}\right)$. Results of $t$ experiments $x_{i j k}$ are recorded 
under
$N\left(\mu_{i j}, \delta^{2}\right), i=1, \cdots, r, j=1, \cdots, s, k=1, \cdots, t$ with mu-

tual independence.

Decompose $x_{i j k}$ into:

$x_{i j k}=\mu_{i j}+\varepsilon_{i j}, i=1, \cdots, r, j=1, \cdots, s, k=1, \cdots, t$

Where, $\varepsilon_{i j k} \sim N\left(\mu_{i j}, \delta^{2}\right)$ with mutual independence:

$\mu=\frac{1}{r s} \sum_{i=1}^{r} \sum_{j=1}^{s} \mu_{i j}, \mu_{i \bullet}=\frac{1}{s} \sum_{j=1}^{s} \mu_{i j}, a_{i}=\mu_{i \bullet}-\mu$

$\mu_{i \bullet}=\frac{1}{r} \sum_{i=1}^{r} \mu_{i j}, \beta_{i}=\mu_{\bullet j}-\mu, \gamma_{i j}=\mu_{i j}-\mu-\alpha_{i}-\beta_{i}$

If there is no interaction between two factors, $t=1$, the process can be simplified. Suppose $\gamma_{i j}=0$, so:

$\mu_{i j}=\mu+\alpha_{i}+\beta_{i}, i=1, \cdots, r, j=1, \cdots, s$

Now the model can be expressed as:

$\left\{\begin{array}{l}x_{i j}=\mu+\alpha_{i}+\beta_{j}+\varepsilon i_{j} \\ \sum_{i=1}^{r} \alpha_{i}=0, \sum_{j=1}^{s} \beta_{j}=0 \\ \varepsilon_{i j k} \sim N\left(0, \delta^{2}\right), i=1, \cdots, r, j=1, \cdots, s\end{array}\right.$

Original hypotheses are:

$H_{01}: \alpha_{i}=0(i=1, \cdots, r)$

$H_{02}: \beta_{j}=0(j=1, \cdots, s)$

$H_{03}: \gamma_{i j}=0(i=1, \cdots, r, j=1, \cdots, s)$

When $H_{01}$ is satisfied:

$F_{A}=\frac{\frac{S_{A}}{r-1}}{\frac{S_{E}}{(r-1)(s-1)}} \sim F(r-1,(r-1)(s-1))$
When $H_{02}$ is satisfied:

$F_{B}=\frac{\frac{S_{B}}{r-1}}{\frac{S_{E}}{(r-1)(s-1)}} \sim F(s-1,(r-1)(s-1))$

Table 2. Calculation results

\begin{tabular}{|c|c|c|c|c|}
\hline & $\begin{array}{l}\text { Squares } \\
\text { sum of } \\
\text { volatility SS }\end{array}$ & $\begin{array}{l}\text { Freedom } \\
\text { degree } f\end{array}$ & $\begin{array}{l}\text { Variance } \\
\mathrm{V}\end{array}$ & $\begin{array}{l}\mathrm{F} \\
\text { value }\end{array}$ \\
\hline $\begin{array}{l}\text { Windsurfer } \\
\text { plate }\end{array}$ & 22.97 & 4 & 6.42 & 7.32 \\
\hline $\begin{array}{l}\text { Mistral } \\
\text { plate }\end{array}$ & 46.17 & 4 & 9.57 & 10.64 \\
\hline $\begin{array}{l}\text { Circular } \\
\text { plate }\end{array}$ & 56.79 & 4 & 13.75 & 15.41 \\
\hline NP plate & 86.33 & 4 & 17.33 & 21.79 \\
\hline
\end{tabular}

The data table of variance analysis can be obtained through the analysis on data with MATLAB.

The analysis diagram of the above data is provided in figure 2:

It is concluded from the data analysis above that the NP plate is more flexible with a heeling angle of zero. Properties of the plate can be performed better with smaller resistance. Hence, it becomes the selection of athletes in modern games. The circular plate is short with a large heeling angle. So, it is preferred by amateurs and the price is relatively lower. The flat bottom plate can be also selected as the plate for competitions. But the properties need to be further improved.

The NP plate has a smaller area and a lighter weight. The maximum camber of the boom is lower with better balance degree. It is easily handled and performs well in competitions. The circular plate has a larger area, but it is hard to handle in a strong wind due to its smaller top and upper maximum camber. 


\section{MATEC Web of Conferences}

2.3 A numerical analysis on influencing factors for performances of windsurfers

\subsubsection{Model of influencing factors of athletic per-} formances based on fuzzy comprehensive evaluation

No matter what kind of sport it is, the performance is mutually influenced by various factors. And windsurfing is no exception. Fluid resistance characteristic, physical ability of athletes, psychological status of athletes, skilled movement, warming-up exercises and plate properties are significant factors for the performance of aquatic athletes.

Here, a fuzzy comprehensive evaluation model of influencing factors for performances of windsurfers is established and influences of the six factors for athletic performances are analyzed so as to determine the most important influencing factor and make preparations for aquatic athletes.

It can be known from a large number of documents that evaluation indicators show that influence performances of aquatic athletes can be classified into six categories: fluid resistance characteristic, physical ability of athletes, psychological status of athletes, skilled movement, warming-up exercises and plate properties

$U=\left\{u_{1}, u_{2}, \cdots, u_{m}\right\}, m=1,2,3, \cdots, 6$

The set of evaluation indicators is ffluid resistance characteristic, physical ability of athletes, psychological status of athletes, skilled movement, warming-up exercise, and plate properties

As for grades of the same system, the main determination method is the expert evaluation method. The set of grades in evaluating the influencing factors for performances of windsurfers is as follows:

$V=\left\{v_{1}, v_{2}, \cdots, v_{n}\right\}, n=1,2,3,4$
The set of evaluation grades of factors for performances of windsurfers is \{very good, good, general, and bad $\}$.

The major representation of weights is:

$w=\left\{\mu_{1}, \mu_{2}, \cdots, \mu_{m}\right\}, m=1,2, \cdots, 6$

Here: $\sum_{m=1}^{6} \mu_{m}=1$

Methods of determining weights of evaluation indicators mainly include the analytic hierarchy process and the normalization method. The normalization formula is:

$w_{i}=\frac{\frac{C_{i}}{\overline{S_{i}}}}{\sum_{i=1}^{n} \frac{C_{i}}{\overline{S_{i}}}},(i=1,2, \cdots, m)$

Weights obtained through the above-mentioned method are:

$W=\{0.04, \quad 0.20, \quad 0.25, \quad 0.30,0.15,0.06\}$

Evaluation methods for the comprehensive evaluation on the matrix $R$ mainly include the expert evaluation method, the analytic hierarchy process and the method of membership degree function.

The expert evaluation method is based on the questionnaire survey and the statistical results of expert evaluation. There are certain errors in the results due to psychological factors. Here, in order to make the calculation results more accurate, the method of membership degree function is adopted to determine the fuzzy relation matrix $R$.

$R=\left(R_{1}, \quad R_{2}, \quad R_{3}, \quad R_{4}, \quad R_{5}, \quad R_{6}\right)^{T}$

The evaluation grade of the $n^{\text {th }}$ level:

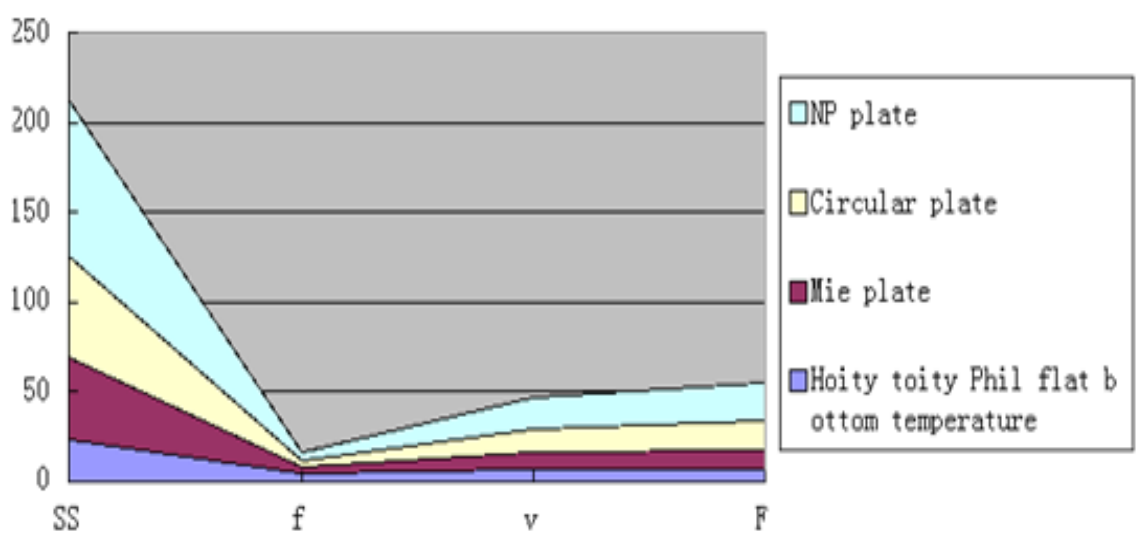

Figure 2. Calculation results 
$\mu_{i n\left(u_{i}\right)}=\left\{\begin{array}{cc}0 & u_{i} \leq v_{i n-1} \\ \frac{u_{i}-v_{i n-1}}{v_{i n}-v_{i n-1}} & v_{i n-1}<u_{i}<v_{i n} \\ 1 & u_{i} \geq v_{i n}\end{array}\right.$

The membership degree of each evaluation parameter can be calculated by substituting data into the above membership degree formula. The fuzzy relation matrix $R$ is constructed as follows:

$$
R=\left(\begin{array}{cccccc}
0.1 & 0.2 & 0.2 & 0.05 & 0.1 & 0.2 \\
0.3 & 0.3 & 0.25 & 0.4 & 0.3 & 0.35 \\
0.5 & 0.4 & 0.5 & 0.45 & 0.4 & 0.35 \\
0.1 & 0.1 & 0.05 & 0.1 & 0.2 & 0.1
\end{array}\right)
$$

It is known that ${ }^{W=\left(\mu_{j}\right)_{1 \times m},},{ }^{R=\left(r_{j i}\right)_{m \times n}}$. According to

$S=w \circ R=\left(\mu_{1}, \mu_{2}, \cdots, \mu_{m}\right) \circ\left(\begin{array}{cccc}r_{11} & r_{12} & \cdots & r_{1 n} \\ r_{21} & r_{22} & \cdots & r_{2 n} \\ \vdots & \vdots & \vdots & \vdots \\ r_{m 1} & r_{m 2} & \cdots & r_{m n}\end{array}\right)=\left(s_{1}, s_{2}, \cdots, s_{n}\right)$

The fuzzy judgment set $S$ can be obtained. Here, "०" is the fuzzy composition operator. The fuzzy operator is $M(\cdot, \oplus)$, namely:

$s_{k}=\min \left(1, \sum_{j=1}^{m} \mu_{j} r_{j k}\right), k=1,2, \cdots, n$

The fuzzy judgment set $S$ can be further obtained which is

$S=\left(\begin{array}{llll}0.441, & 0.298, \quad 0.321, & 0.103, & 0.221\end{array}\right.$

It can be known from $M=\max \left(S_{1}, S_{2}, \cdots, S_{n}\right)$ that:

$M=\max \left(S_{1}, S_{2}, \cdots, S_{n}\right)=0.441$

It can be concluded from the calculation results that the fluid resistance characteristic is a key factor for the performance. In addition, the factors mentioned above are studied from the angle of athletes and sailboard properties. Physical environment factors like temperature, climate, and altitude also have an impact on windsurfers and their performances.

\subsubsection{Model of athletic performance and fluid re- sistance characteristic based on the correlation analysis}

Windsurfing has opened up a new field of aquatics. All the sport equipment can be used for aquatic leisure. However, dynamic properties of sailboard change with the influence of resistance. In order to study the influence of resistance on dynamic properties of sailboard, the correlation analysis is adopted here to calculate the relationship between the two. Conclusions are drawn accordingly.

The Pearson correlation coefficient is a kind of method of correlation analysis. It is used to represent the similarity between two variables, which can be obtained through quantitative calculation. The formula is as follows:

$$
\begin{aligned}
& \rho(X, Y)=\frac{\operatorname{cov}(X, Y)}{\sigma_{x} \sigma_{y}}=\frac{E\left(\left(X-\mu_{x}\right)\left(Y-\mu_{y}\right)\right)}{\sigma_{x} \sigma_{y}} \\
& \mu_{x}=E(X), \sigma_{X}{ }^{2}=E\left(X-\mu_{x}\right)^{2}=E\left(X^{2}\right)-E^{2}(X)
\end{aligned}
$$

So, the Pearson correlation coefficient can be also expressed as:

$$
\rho(X, Y)=\frac{E(X Y)-E(X) E(Y)}{\sqrt{E\left(X^{2}\right)-E^{2}(X)} \sqrt{E\left(Y^{2}\right)-E^{2}(Y)}}
$$

It indicates that the correlation of the two is large or the two are closely related when the Pearson correlation coefficient of the two variables approaches 1 or -1 . If it approaches 1 , the two are positively correlated. If it approaches -1 , the two are negatively correlated.

Here, the air resistance is represented by the wind speed and the resistance of sailboard in water is represented by water velocity. Meanwhile, attributes of sailboard are also introduced in order to compare the influence of resistance, namely the comparison of the

\begin{tabular}{|c|c|c|c|c|c|}
\hline \multicolumn{2}{|c|}{ Control variables } & $\begin{array}{l}\text { Speed per } \\
\text { hour of } \\
\text { sailboard }\end{array}$ & $\begin{array}{l}\text { Air } \\
\text { resistance }\end{array}$ & $\begin{array}{l}\text { Water } \\
\text { velocity }\end{array}$ & $\begin{array}{l}\text { Surface } \\
\text { roughness }\end{array}$ \\
\hline \multirow{3}{*}{$\begin{array}{l}\text { Speed per } \\
\text { hour of } \\
\text { sailboard }\end{array}$} & $\begin{array}{l}\text { Pearson } \\
\text { correlation }\end{array}$ & 1.000 & .801 & .885 & .144 \\
\hline & $\begin{array}{l}\text { Significance } \\
\text { (bilateral) }\end{array}$ & & .856 & .790 & .295 \\
\hline & $\mathrm{df}$ & 0 & 2 & 2 & 2 \\
\hline
\end{tabular}
surface roughness of sailboard. Data can be acquired as follows:

Table 3. Data correlation

It can be seen that both the air resistance and the resistance of sailboard in water are the main factors influencing the speed per hour of sailboard. For this reason, the motion process of sailboard can be simulated with the software $C F D$ of fluid mechanics. Velocity changes of sailboard can be analyzed with consideration of air resistance and water velocity, so that studies on mechanical features of windsurfing can be more thorough.

\subsection{Regional difference of aquatic events}

As for aquatic events, regional difference is also an important external factor that should be taken into account in the study on the fluid mechanics. Economic development and environmental features are different in various regions, so the development situations of aquatics and the fluid mechanics characteristics are different as well.

Gold medals distributions of aquatics of the $11^{\text {th }}$ National Games in different regions are provided in the following table. The influence of regional factors is observed by comparing the gold medal distribution in each region. 


\section{MATEC Web of Conferences}

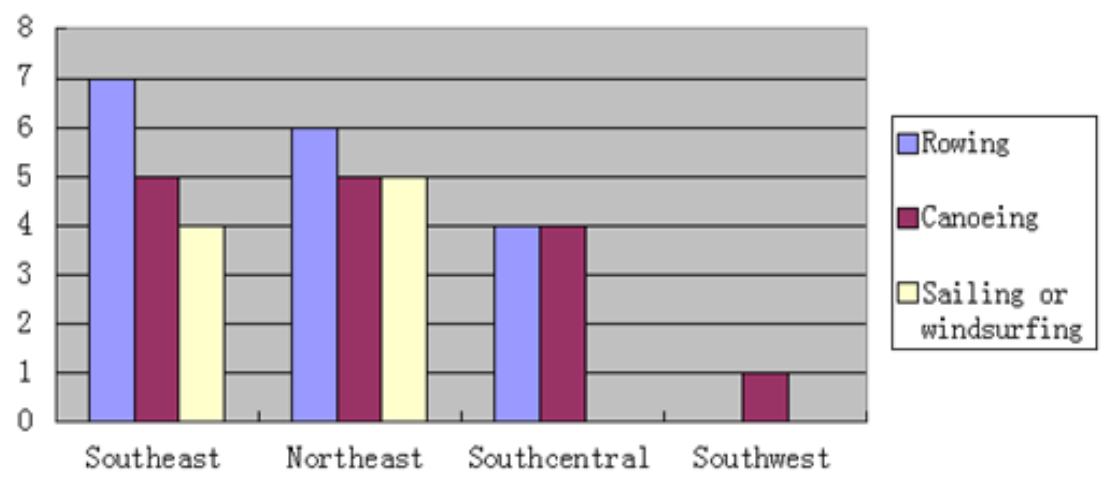

Figure 3. The National Games gold medal of the regional water distribution

Table 4. Gold medals distributions of aquatics of the $11^{\text {th }}$ National Games in different regions

\begin{tabular}{|c|c|c|c|}
\hline & Rowing & Canoeing & Sailing/Windsurfing \\
\hline Southeast & 7 & 5 & 4 \\
\hline Northeast & 6 & 5 & 5 \\
\hline $\begin{array}{l}\text { South } \\
\text { Central }\end{array}$ & 4 & 4 & 0 \\
\hline Southwest & 0 & 1 & 0 \\
\hline
\end{tabular}

The statistical diagram is drawn as follows in order to compare features of the gold medal distribution in different regions.

It can be concluded from the histogram in figure 3 that there are large regional differences in aquatic events. Thus, the geographical conditions and the environmental factors in each region are key factors that should be considered in the study on the fluid mechanics features of aquatics.

\section{CONCLUSIONS}

The analysis in this paper is carried out based on the fluid mechanics performance. The fluid mechanics is an essential application method as well as the theoretical basis in the study on dynamic characteristics of aquatic events. Therefore, this paper makes a brief introduction on the fluid mechanics, which is the research basis of the paper.

In addition, the close relationship between the fluid mechanics and the mechanical analysis on aquatics is confirmed through the analysis on windsurfing. The following conclusions can be drawn through the establishment of a mathematical model: The main reason that influences windsurfing is the resistance characteristic; different sailboards with various parameters have different fluid mechanics features. It can be known from the variance analysis that the best performance of NP plate and a relatively small resistance should be the direction of sailboard design.

Finally, the restraining factor of aquatic events is taken into account from the aspect of external factors, namely the regional difference. This is also a key that should be considered in the analysis of aquatics with fluid mechanics.

\section{REFERENCES}

[1] Ma, Y. 2012. Research progress of the fluid mechanics of aquatic equipment in China, Journal of Physical Education.

[2] Ma, Y. 2011. The application of multi-disciplinary design optimization in aquatic events, Journal of Nanjing Sport Institute.

[3] Zheng, W.T. 2012. Application status of fluid mechanics in aquatics in China, China Meeting.

[4] Zheng, W.T. 2013. A literature review on sports engineering at home and abroad, Journal of Wuhan Institute of Physical Education.

[5] Zhang, D.Y. 2012. A Study on the Numerical Simulation of the Hydrodynamics Performance of Rowing Paddle, Wuhan University of Technology.

[6] Li, B.L. 2011. Development Characteristics of Aquatic Olympic Events in China and the Analysis on Training and Management Factors, Qufu Normal University.

[7] He, H.F. 2012. A Numerical Simulation of the Aerodynamic Performance of Sail Waving, Wuhan University of Technology.

[8] Bai, K.X. 2005. A Study on the Fluid Mechanics Performance of Sailboard and the Optimal Route, Wuhan University of Technology.

[9] Liu, L.N. 2012. A Study on the Numerical Simulation Method of the Aerodynamic Performance of Sail Waving of 470 Sailing, Wuhan Institute of Physical Education.

[10] Ge, X.F. 2011. Research progress of fluid mechanics in physical exercises, Journal of Shandong Physical Education Institute.

[11]Han, J.R. 1999. A study on the fluid mechanics performance of sailing and canoeing equipment, Journal of Wuhan Institute of Physical Education. 